\title{
AVALIAÇÃO DAS PROPRIEDADES FÍSICO-MECÂNICAS DE PAINÉIS DE CIMENTO-MADEIRA UTILIZANDO FARINHA DE MADEIRA COM GRANULOMETRIA CONTROLADA
}

\author{
Adalberto Matoski*, Setsuo Iwakiri** \\ *Eng. Civil, Dr., UTFPR - adalbert@cefetpr.br \\ **Eng. Florestal, Dr., Depto. de Engenharia e Tecnologia Florestal, UFPR - setsuo@floresta.ufpr.br \\ Recebido para publicação: 13/03/2006 - Aceito para publicação: 01/04/2007
}

\begin{abstract}
Resumo
Este trabalho teve como objetivo o estudo da resistência à compressão e flexão de painéis de cimentomadeira utilizando farinha de madeira de Pinus spp. com granulometria controlada proveniente de reaproveitamento do rejeito de indústrias madeireiras. O material, na forma de pequenas partículas (pó), com dimensões menores que $0,8 \mathrm{~mm}$, foi gerado pelo processo de moagem com controle da granulometria. Este trabalho está dividido em duas etapas distintas. A primeira etapa consiste no estudo das propriedades físico-mecânicas para painéis fabricados com teor de $25 \%$ de farinha. A segunda etapa consiste no estudo das mesmas propriedades, considerando o teor de $36 \%$ de farinha de madeira. Em ambas as etapas foram utilizadas quatro distribuições granulométricas distintas combinadas com cloreto de cálcio, como acelerador da cura. Verificou-se que a farinha de menor tamanho médio de partículas obteve resultados inferiores aos obtidos com as farinhas de maior tamanho médio, ou seja, granulometria mais grossa.

Palavras-chave: Madeira; cimento; compósitos; painéis.
\end{abstract}

\begin{abstract}
Evaluation of physical and mechanical properties of wood cement panel using wood flour with controlled granulometry. This work aims to contribute to wood-cement panels research using milling wood, also known as wood flour, whose origin are lumber industries rejects. The usable material are Pinus spp species particles, where the obtained staple fibers were relatively short and inflexible, keeping, however, its resistance. The material in the form of small particles was generated by the process controled particle size milling. This work was divided in two distinct stages: the first stage consisted in wood-cement panels work out, with $25 \%$ of wood flour. The second stage of the experiment consisted in wood-cement panels work out, with $36 \%$ of wood flour. In both stages were used four different granulometry distributions combined with calcium chloride as hardener. The finest flour showed the lower results in comparison with the coarsest flour.

Keywords: Wood-cement; composites; panels.
\end{abstract}

\section{INTRODUÇÃO}

A busca pela otimização do sistema construtivo é cada vez maior em função da necessidade de se reduzir os custos e minimizar os desperdícios. Os painéis de madeira estão na classe de produtos que auxiliam a industrialização da construção civil, pois podem ser utilizados na execução de paredes, pisos e coberturas de forma modulada. Além da facilidade de sua utilização, a madeira tem um forte apelo ecológico e baixo consumo de energia no processo de industrialização.

As características físico-mecânicas são indicadores para a empregabilidade dos painéis de cimento-madeira, pois esses painéis podem ser serrados, pregados, parafusados ou colados, permitindo assim larga utilização. Essas mesmas características permitem que sejam pintados, chapiscados, rebocados e revestidos com outros tipos de materiais. A versatilidade desse material permite que o fabricante agregue valor a esses painéis na medida em que, em vez de brutos, eles podem ser entregues lixados, pintados ou revestidos, permitindo que sejam utilizados diretamente como material de acabamento. 
No Brasil, as pesquisas, como, por exemplo, a de Grandi (1995), têm sido dirigidas para o reaproveitamento de material rejeitado por outros processos produtivos. Além de resíduos de madeira, outros materiais, como fibra de sisal, fibra de coco, fibra da bananeira e até a fibra de couro, têm sido utilizadas nessas pesquisas.

O objetivo principal deste trabalho foi avaliar a resistência à compressão e flexão de painéis de cimento-madeira e determinar as características físicas de absorção de água, inchamento, módulo de ruptura, módulo de elasticidade e densidade dos painéis de cimento-madeira produzidos com farinha de madeira com distribuição granulométrica controlada. Utilizou-se, para isso, cimento de alta resistência inicial e cloreto de cálcio como acelerador de cura. Este trabalho também compara os resultados obtidos com aqueles apresentados por outros autores que pesquisaram o compósito de cimento-madeira.

Justifica-se o estudo dessas propriedades físico-mecânicas, pois são as que indicam a possibilidade de uso dos painéis de cimento-madeira na indústria da construção civil. Ainda, esses painéis possibilitam o uso de rejeitos de madeira que existem em grande quantidade no Brasil e que na maioria dos casos são queimados, devolvendo todo o $\mathrm{CO}_{2}$ para a atmosfera.

\section{REVISÃO DA LITERATURA}

O painel de cimento-madeira surgiu na Europa, como elemento construtivo, no final dos anos setenta do século XX. Os painéis cimento-madeira têm tido boa aceitação no mundo, pois busca-se através dessa mistura reunir propriedades desejáveis da madeira e do cimento (COATES, 1994).

O termo compósito pode ser definido como um material composto por dois ou mais constituintes, que possui uma fase reforçada, como por exemplo os painéis de cimento-madeira em que as partículas de madeira estão envolvidas por uma fase ligante, o cimento. A vantagem desse compósito está na resistência e na dureza relativamente maiores que a dos materiais separados, além de sua baixa densidade.

No compósito, na fase ligante, o cimento transmite o esforço entre as partículas de madeira, mantendo-as protegidas do meio e permitindo sua orientação apropriada. Por sua vez, a madeira, além de aumentar a resistência à tração, contribui para redução da densidade e do custo.

Os compósitos de cimento-madeira apresentam vantagens, como sua baixa densidade quando comparada à do concreto, seu melhor desempenho para resistir às intempéries, ao fogo, aos fungos e aos ataques de insetos, neste caso em relação à madeira. Wei e Tomita (2000) sugerem que podem até substituir o tijolo e o concreto em determinadas situações.

Beraldo et al. (1998) estudaram, para madeira de Eucalyptus grandis, a resistência mecânica de corpos-de-prova cilíndricos produzidos com as seguintes condições experimentais: densidade aparente de $275 \mathrm{~kg} / \mathrm{m}^{3}$; módulo de finura $(\mathrm{MF})$ de 4,30; diâmetro máximo das partículas de 2,4 mm; relação cimento:madeira de 13:1. Esse trabalho apresentou os melhores resultados para a combinação do cimento CP V ARI e aditivo à base de cloreto de cálcio, com valores de 15,9 MPa.

Apesar de um mesmo módulo de finura representar um número muito grande de distribuições de tamanhos de partículas completamente diferentes, ele pode ser útil para detectar pequenas variações no agregado de mesma origem, bem como dar indicação do comportamento provável da mistura.

Entre os fatores com os quais a granulometria do agregado influencia nas propriedades do compósito, tem-se a sua superfície específica, que influi na quantidade de água necessária para molhar sua superfície (MOSLEMI, GARCIA; HOFSTRAND, 1983).

Outro aspecto importante a ser considerado é a proporção cimento:madeira do compósito. Quantidades maiores de cimento elevam o custo final e uma maior proporção de madeira na mistura tem a vantagem de reduzir a densidade do painel (MOSLEMI, GARCIA; HOFSTRAND, 1983).

As reações que tornam o cimento um elemento ligante ocorrem na pasta de água e cimento, na qual os aluminatos e silicatos formam produtos hidratados, que com o passar do tempo dão origem a uma massa firme e resistente. As características físicas e químicas da madeira são aspectos fundamentais que têm grande influência no produto final, sobretudo porque nem todas as espécies reagem favoravelmente com o cimento Portland, devido ao tipo e à quantidade de extrativos presentes na madeira (ALBERTO et al., 2000).

A densidade da madeira, segundo Iwakiri et al. (2001), deve ser de média a baixa, para assegurar a razão de compactação da chapa dentro de níveis adequados para a densificação e consolidação do material. 
As dimensões das partículas exercem influência marcante sobre as propriedades das chapas, sobretudo quando se referem à flexão. As dimensões adequadas das partículas no processo industrial devem estar entre 2 e $20 \mathrm{~mm}$ de comprimento, 0,2 e 2,5 $\mathrm{mm}$ de largura e 0,3 e $0,9 \mathrm{~mm}$ de espessura (IWAKIRI et al., 2001). Outro fator no qual o tamanho da partícula exerce influência é o consumo de cimento, pois quanto maior a superfície específica das partículas maior deve ser a quantidade de pasta de cimento para envolvê-las e, conseqüentemente, maior a quantidade de água necessária para a formação dessa pasta.

\section{MATERIAIS E MÉTODOS}

\section{Materiais}

O material utilizado nesta pesquisa foi madeira de Pinus spp. na forma de farinha de madeira com granulometria controlada, obtido através da transformação mecânica de rejeitos em escala comercial na Indústria Brasileira de Farinha de Madeira.

A farinha de madeira foi classificada de acordo com sua distribuição granulométrica, tomando-se como parâmetro o módulo de finura. O módulo de finura é definido como a soma das percentagens acumuladas na série normal de peneiras dividida por 100, conforme norma NBR 7217 (1982). Para este estudo, foram utilizadas quatro granulometrias distintas para a produção de painéis cimento-madeira, conforme apresentado na figura 1 .

Os valores médios de módulo de finura para quatro diferentes distribuições granulométricas da farinha de madeira estão apresentados na tabela 1.

Tabela 1. Módulo de finura das farinhas utilizadas.

Table 1. Granulometry distribution of wood flour.

\begin{tabular}{lc}
\hline Identificação & Módulo de finura \\
\hline Farinha 1 & 0,28 \\
Farinha 2 & 0,75 \\
Farinha 3 & 1,50 \\
Farinha 4 & 1,57 \\
\hline
\end{tabular}

Os menores valores do módulo de finura indicam as farinhas mais finas, conforme também se observa na figura 1. Ainda, a título de comparação, Beraldo et al. (1998) trabalharam com o módulo de finura de 4,30, mostrando que as partículas utilizadas neste trabalho são menores.

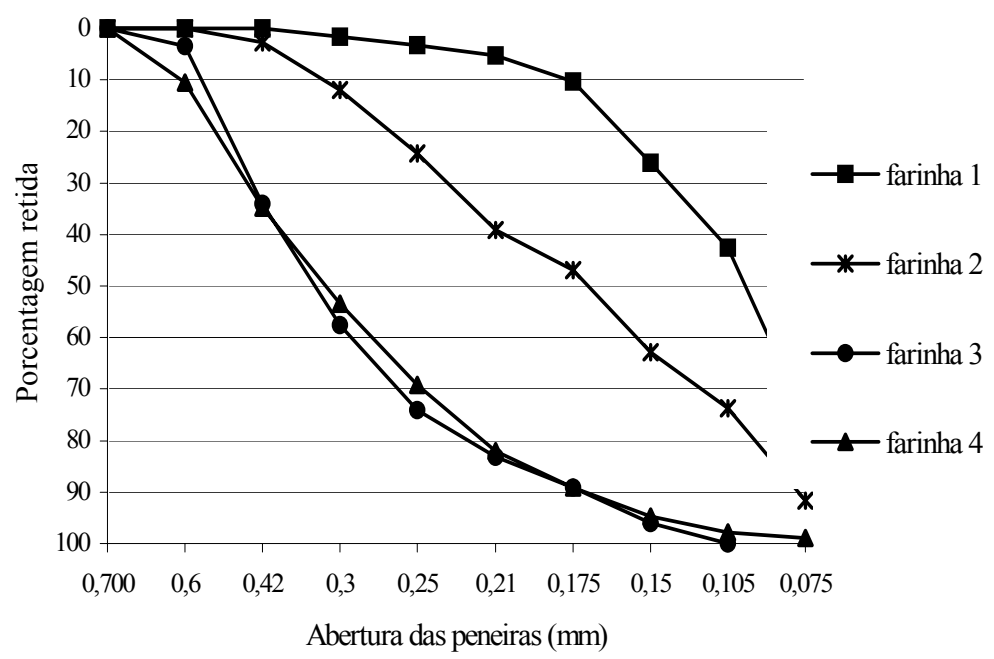

Figura 1. Análise granulométrica da farinha de madeira.

Figure 1. Granulometry analysis of wood flour. 
A figura 1 indica que as farinhas de números 1 e 2 são as mais finas, já que têm mais de $90 \%$ do material passante pela malha $0,3 \mathrm{~mm}$. Já as farinhas de números 3 e 4 são mais grossas, pois têm apenas $50 \%$ do material passante pela malha $0,3 \mathrm{~mm}$.

O diâmetro médio para $50 \%$ de retenção é de $0,3 \mathrm{~mm}$ para a farinha 3 e de $0,33 \mathrm{~mm}$ para a farinha 4. Para a farinha de número 2, o diâmetro médio correspondente é de $0,175 \mathrm{~mm}$, e finalmente, para a farinha mais fina, o diâmetro médio equivalente a $50 \%$ de retenção é $0,075 \mathrm{~mm}$.

Após a classificação, o material foi acondicionado em sacos lacrados e mantido à temperatura ambiente até a confecção dos corpos-de-prova.

A determinação da densidade foi realizada de acordo com procedimentos da norma NBR 7251 (1982). Para a determinação do teor de umidade, foram retiradas amostras da farinha de madeira de cada granulometria.

A água utilizada foi a fornecida diretamente pela rede pública de distribuição, por uma questão de economia e praticidade.

$\mathrm{O}$ cimento utilizado foi o CP V ARI, pelo fato de que em outros experimentos ofereceu boa compatibilidade com a madeira do pinus, conforme citado por Alberto et al. (2000), e também por atingir elevadas resistências em pouca idade, fato esse vantajoso, pois economiza tempo. A especificação do cimento está de acordo com a NBR 11578 (1990). Os cimentos foram adquiridos em sacos de $50 \mathrm{~kg}$, conforme são vendidos comercialmente, permanecendo em sua embalagem original, até seu uso, uma vez que após abertos foram utilizados em menos de uma semana.

$\mathrm{O}$ aditivo utilizado foi o cloreto de cálcio $\left(\mathrm{CaCl}_{2}\right)$, adquirido no comércio, pois é comumente utilizado como acelerador de cura de concretos e argamassas à base de cimento.

\section{Manufatura dos painéis cimento-madeira}

Para cada distribuição granulométrica, foram moldados três painéis simultaneamente, com teor de $25 \%$ de pó de madeira e com as seguintes dimensões: $385 \mathrm{~mm}$ de largura, $505 \mathrm{~mm}$ de comprimento e $15 \mathrm{~mm}$ de espessura. A tabela 2 apresenta as quantidades de materiais utilizados para a moldagem dos painéis.

Tabela 2. Quantidade de material utilizado na moldagem de painéis de cimento-madeira.

Table 2. Quantity of material used for the production of the wood cement panels.

\begin{tabular}{lc}
\hline Material & Quantidade \\
\hline Cimento & $3000 \mathrm{~g}$ \\
Farinha de madeira & $750 \mathrm{~g}$ \\
Aditivo & $120 \mathrm{~g}$ \\
Água & variável \\
\hline
\end{tabular}

A relação cimento-madeira foi de 4:1 e o teor de aditivos foi de $4 \%$ em relação à massa de cimento. Foram mantidos constantes durante todo o experimento para todas as farinhas. $\mathrm{O}$ teor de umidade presente na madeira foi determinado através da adaptação da NBR 7211 (1982), e como tem influência direta na quantidade de água adicionada na mistura, foi realizada a correção, conforme equação [1] também utilizada por Fan et al. (1999).

$$
\text { Água corrigida }=(\mathrm{F} \mathrm{a} / \mathrm{c}) \mathrm{C}+\mathrm{M}(0,30-\mathrm{TU})[1]
$$

Sendo:

$\mathrm{F}$ a/c $=$ fator água-cimento.

$\mathrm{C}=$ quantidade de cimento em gramas.

$\mathrm{M}=$ quantidade de madeira em gramas.

$\mathrm{TU}=$ teor de umidade de madeira $(\%)$.

A densidade adotada para os painéis foi de $2,0 \mathrm{~g} / \mathrm{cm}^{3}$. Esse valor foi adotado em função das características granulométricas da farinha de madeira.

Após a pesagem, o material foi misturado em betoneira, obedecendo à seguinte metodologia: inicialmente foi adicionada metade da farinha e, em seqüência, todo o cimento e depois o restante da 
madeira. Após a homogeneização da mistura, foi adicionada a água já previamente misturada com o aditivo, utilizando-se pistola com sistema pressurizado. Na seqüência, o material foi retirado da betoneira, pesado e moldado para a prensagem.

Os painéis foram prensados à temperatura ambiente, com pressão de $4 \mathrm{MPa}$, e imediatamente grampeados e mantidos por um período de 24 horas para processo de endurecimento. Após essa fase, os painéis foram retirados do aparato de grampeamento e empilhados na câmara climática à temperatura de $20 \pm 1{ }^{\circ} \mathrm{C}$ e umidade relativa de $65 \pm 5 \%$, por um período de 28 dias, para completar o processo de maturação.

\section{Determinação das propriedades dos painéis}

Foram moldados 48 painéis para a avaliação das propriedades, sendo extraídos de cada painel seis corpos-de-prova para realização dos ensaios de absorção e inchamento em espessura, e 4 corpos-deprova para os ensaios de compressão paralela. Essa quantidade está de acordo com as normas ASTM 1037-34 e 1037-100 (1982). Por sua vez, os ensaios de flexão estática e de ligação interna foram realizados de acordo com a EN 1058 CEN (1995) e ASTM 1037 (1982), respectivamente, com a mesma quantidade de corpos-de-prova utilizada nos ensaios de compressão paralela.

Os corpos-de-prova, no momento do ensaio, estavam com o teor de umidade de $65 \%$, pois foram rompidos em ambiente com temperatura e umidade controladas, conforme acima citado.

\section{Análise estatística}

A determinação do comportamento dos painéis para a compressão axial, flexão estática, ligação interna, absorção e inchamento foi realizada através da análise da variância, para comparação de médias.

\section{RESULTADOS E DISCUSSÃO}

\section{Absorção de água e inchamento em espessura}

Os resultados médios da absorção de água e do inchamento em espessura, após o período de duas horas em imersão para seis corpos-de-prova, podem ser observados na tabela 3.

Tabela 3. Resultados da absorção de água e inchamento em espessura dos painéis feitos com $25 \%$ de farinha de madeira (2 horas).

Table 3. Results of water absorption and thickness swelling ( 2 hours) of the panels produced with $25 \%$ of wood flour.

\begin{tabular}{lcccc}
\hline & \multicolumn{2}{c}{ Absorção de água } & \multicolumn{2}{c}{ Inchamento } \\
\cline { 2 - 5 } & \multicolumn{2}{c}{ 2 horas } & \multicolumn{2}{c}{ 2 horas } \\
\hline \multirow{2}{*}{ Granulometria } & $\begin{array}{c}\text { Média } \\
\mathbf{( \% )}\end{array}$ & $\begin{array}{c}\text { CV } \\
\mathbf{( \% )}\end{array}$ & $\begin{array}{c}\text { Média } \\
\mathbf{( \% )}\end{array}$ & $\begin{array}{c}\text { CV } \\
\mathbf{( \% )}\end{array}$ \\
\hline Farinha 1 & $3,47 \mathrm{a}$ & 54,93 & $0,85 \mathrm{a}$ & 62,27 \\
Farinha 2 & $2,53 \mathrm{a}$ & 71,57 & $0,81 \mathrm{a}$ & 56,53 \\
Farinha 3 & $3,12 \mathrm{a}$ & 75,75 & $0,76 \mathrm{a}$ & 59,73 \\
Farinha 4 & 2,49 a & 71,11 & $0,72 \mathrm{a}$ & 63,59 \\
\hline Letras diferentes denotam diferenças estatísticas ao nível de 5 \% de significância.
\end{tabular}

Observa-se que os valores percentuais de absorção de água ficaram bastante próximos, o mesmo ocorrendo com o inchamento em espessura. Outra constatação é o elevado coeficiente de variação, para ambas as propriedades, revelando grande variabilidade em seu comportamento. Verificou-se, após a análise da variância, que não existe diferença significativa, conforme apresentado na tabela 2, para os valores obtidos em função das diversas granulometrias.

Na tabela 4 estão apresentados os valores médios e os coeficientes de variação da absorção de água e inchamento em espessura, considerando os valores obtidos para um período de 24 horas de imersão.

Observa-se também que não houve diferença significativa entre os valores médios para ambas as propriedades. Em outras palavras, a variação da granulometria, no padrão adotado, não interferiu no resultado tanto da absorção de água quanto do inchamento em espessura. 
Tabela 4. Resultado da absorção de água e inchamento em espessura dos painéis com $25 \%$ de farinha de madeira (24 horas).

Table 4. Results of water distribution and thickness swelling (24 hours) of the panels produced with 25 $\%$ of wood flour.

\begin{tabular}{lcccc}
\hline & \multicolumn{2}{c}{ Absorção de água } & \multicolumn{2}{c}{ Inchamento } \\
\cline { 2 - 5 } & \multicolumn{2}{c}{$\mathbf{2 4}$ horas } & \multicolumn{2}{c}{$\mathbf{2 4}$ horas } \\
\hline \multirow{2}{*}{ Granulometria } & $\begin{array}{c}\text { Média } \\
(\%)\end{array}$ & $\begin{array}{c}\text { CV } \\
(\%)\end{array}$ & $\begin{array}{c}\text { Média } \\
(\%)\end{array}$ & $\begin{array}{c}\text { CV } \\
(\%)\end{array}$ \\
\hline Farinha 1 & 6,06 a & 39,03 & $1,27 \mathrm{a}$ & 46,65 \\
Farinha 2 & $4,71 \mathrm{a}$ & 42,57 & $1,28 \mathrm{a}$ & 43,07 \\
Farinha 3 & $5,97 \mathrm{a}$ & 44,60 & $1,19 \mathrm{a}$ & 43,24 \\
Farinha 4 & $5,52 \mathrm{a}$ & 39,68 & $1,22 \mathrm{a}$ & 40,79 \\
\hline
\end{tabular}

Letras diferentes denotam diferenças estatísticas ao nível de $5 \%$ de significância.

Os valores da tabela 2 estão próximos aos obtidos por Venta (1994), que obteve absorção média de 3,5\% também para o período de duas horas. Os baixos valores para absorção de água, que variaram entre $4,71 \%$ e $6,06 \%$, justificam-se pelo fato de se tratar de um material com $75 \%$ de cimento e $25 \%$ de madeira, no qual o cimento tem expansão naturalmente baixa. Mesma justificativa pode ser aplicada ao inchamento em espessura, cujos valores variaram entre $1,19 \%$ e $1,28 \%$.

Tensão de ruptura e módulo de elasticidade na compressão paralela (MOE)

Para um total de 12 corpos-de-prova para cada tipo de farinha, os valores médios da tensão de ruptura e do módulo de elasticidade estão apresentados na tabela 5.

Tabela 5. Efeito da granulometria sobre a tensão de ruptura na compressão paralela dos painéis. Table 5. Effect of granulometry on the parallel compression strength of the panels.

\begin{tabular}{lcccc}
\hline Granulometria & $\begin{array}{c}\text { MOR } \\
\text { (MPa) }\end{array}$ & $\begin{array}{c}\text { CV } \\
(\%)\end{array}$ & $\begin{array}{c}\text { MOE } \\
\mathbf{( M P a )}\end{array}$ & $\begin{array}{c}\text { CV } \\
(\%)\end{array}$ \\
\hline Farinha 1 & $14,13 \mathrm{a}$ & 24,08 & $2332,86 \mathrm{a}$ & 38,92 \\
Farinha 2 & $17,15 \mathrm{~b}$ & 19,90 & $2823,80 \mathrm{~b}$ & 27,52 \\
Farinha 3 & $15,84 \mathrm{~b}$ & 27,83 & $3378,26 \mathrm{c}$ & 32,44 \\
Farinha 4 & $16,18 \mathrm{~b}$ & 28,33 & $2898,75 \mathrm{~b}$ & 30,06 \\
\hline
\end{tabular}

Letras diferentes denotam diferenças estatísticas ao nível de $5 \%$ de significância. MOE: Módulo de Elasticidade.

De acordo com a tabela 4, a tensão de ruptura é menor para o painel composto pela farinha 1 , que obteve valores significativamente menores que os das demais farinhas. A granulometria mais fina reduziu a trabalhabilidade, e pelo fato de ter maior absorção de água levou a uma menor resistência. Essa distribuição granulométrica obteve também o módulo de elasticidade mais baixo. A análise estatística demonstrou que ocorre o mesmo comportamento no módulo de elasticidade, ou seja, a farinha mais fina diferenciou-se significativamente das demais farinhas. Deve-se considerar, no entanto, que ainda o valor de 14,1 MPa da farinha mais fina é alto quando comparado a resultados apresentados por Grandi (1995), que encontrou valores médios em torno de $10 \mathrm{MPa}$.

\section{Tensão de ruptura e módulo de elasticidade em flexão estática}

Na tabela 6, observa-se o resultado do ensaio para 12 corpos-de-prova da tensão de ruptura e do módulo de elasticidade obtidos para as quatro distribuições granulométricas.

Os valores da tensão de ruptura em ensaios de flexão apontam os menores valores para os painéis produzidos com o pó mais fino. A distribuição granulométrica da farinha 3 é a que apresentou o maior valor. A análise da variância mostrou que há diferença significativa entre os diversos tipos de distribuição granulométrica para essa propriedade. A farinha 1 (mais fina) apresentou o menor valor. A mesma análise feita para o módulo de elasticidade mostrou que não há diferença estatisticamente significativa entre as distribuições granulométricas das farinhas 2 e 4, apresentando diferenças significativas para as demais comparações. A distribuição granulométrica da farinha 1 obteve o menor valor, porém semelhante ao da farinha 3. 
Tabela 6. Valores da Tensão de Ruptura (MOR) e do Módulo de Elasticidade (MOE) em flexão estática dos painéis para diferentes granulometrias.

Table 6. Results of modulus of rupture (MOR) and modulus of elasticity in static bending of the panel for different granulometry.

\begin{tabular}{ccccc}
\hline Granulometria & $\begin{array}{c}\text { Tensão } \\
\text { (MPa) }\end{array}$ & $\begin{array}{c}\text { CV } \\
(\%)\end{array}$ & $\begin{array}{c}\text { MOE } \\
\text { (MPa) }\end{array}$ & $\begin{array}{r}\text { CV } \\
(\%)\end{array}$ \\
\hline Farinha 1 & $3,82 \mathrm{a}$ & 24,46 & $2288,3 \mathrm{a}$ & 29,60 \\
Farinha 2 & $4,65 \mathrm{~b}$ & 19,79 & $2858,5 \mathrm{~b}$ & 23,76 \\
Farinha 3 & $5,74 \mathrm{c}$ & 15,84 & $2377,2 \mathrm{a}$ & 31,54 \\
Farinha 4 & $4,50 \mathrm{~b}$ & 27,01 & $2666,5 \mathrm{~b}$ & 40,61 \\
\hline
\end{tabular}

Segundo Latorraca (2000), a granulometria muito fina da farinha de madeira gera um efeito inibidor da cura do cimento, e por isso leva a resultados mais baixos na tensão de ruptura e no módulo de elasticidade em flexão estática. No entanto, outro fator que deve ser considerado é o grau de compactação do compósito, que pode compensar o efeito da redução do comprimento das fibras da madeira quando se utiliza a distribuição granulométrica adotada neste trabalho.

\section{Relação entre a Densidade, Tensão de Ruptura e Módulo de Elasticidade na flexão}

O comportamento da correlação entre as densidades médias e a tensão de ruptura na flexão tem a mesma tendência observada por Wolfe e Gnolli (1999). Ou seja, há uma tendência ao crescimento dos valores com o aumento da densidade. A figura 2 mostra a relação obtida entre o módulo de ruptura e a densidade. Os valores utilizados para a determinação dessa relação são os valores médios da tensão de ruptura e da densidade para todas as farinhas com teor definido anteriormente. Os valores foram obtidos com o teor de umidade dos corpos-de-prova em equilíbrio com o ambiente, uma vez que todos os ensaios foram realizados em câmara climatizada.



Figura 2. Correlação entre a densidade e a resistência à flexão estática dos painéis.

Figure 2. Correlation between density and the flexure strength of the panels.

O coeficiente de correlação obtido é bom, mostrando assim que quanto mais compactado for o corpo-de-prova maior a resistência à flexão. A densidade é inversamente proporcional ao fator água/cimento, devido ao fato de que quanto mais água maior os espaços vazios, o que leva a uma menor resistência. Pode-se justificar dessa forma a elevada interação entre a matriz de cimento e as partículas de madeira, pois quanto menor a partícula menor é o número de vazios e, conseqüentemente, maior a resistência.

\section{Ligação interna}

A tabela 7 mostra os resultados obtidos para a ligação interna para cada distribuição granulométrica, com valores médios obtidos para 18 repetições. 
Tabela 7. Valores da ligação interna dos painéis para farinhas com diferentes distribuições granulométricas.

Table 7. Results of internal bond of the panels to flours with different granulometry distributions.

\begin{tabular}{lccc}
\hline Granulometria & $\begin{array}{c}\text { Diâmetro a 50 \% } \\
(\mathbf{m m})\end{array}$ & $\begin{array}{c}\text { Ligação interna } \\
\text { (MPa) }\end{array}$ & $\begin{array}{c}\text { Coeficiente de variação } \\
\text { (\%) }\end{array}$ \\
\hline Farinha 1 & 0,075 & $0,30 \mathrm{a}$ & 36,30 \\
Farinha 2 & 0,175 & $0,45 \mathrm{~b}$ & 36,39 \\
Farinha 3 & 0,300 & $0,43 \mathrm{~b}$ & 33,74 \\
Farinha 4 & 0,330 & $0,54 \mathrm{c}$ & 29,50 \\
\hline
\end{tabular}

Letras diferentes denotam diferenças estatísticas ao nível de 5 \% de significância.

Observa-se, nessa tabela, que os valores da ligação interna crescem apenas para o intervalo de distribuição granulométrica da farinha 1 para a farinha 2, ocorrendo o mesmo no intervalo das farinhas 2 e 3 para a farinha 4. A análise estatística mostrou que há diferença significativa entre a granulometria mais fina e as demais granulometrias, sendo a da Farinha 1 a de menor valor. Não há diferença estatisticamente significativa entre as distribuições granulométricas para as farinhas 2 e 3 . A diferença é significativa para a distribuição granulométrica da farinha 4. Observa-se também que a distribuição granulométrica apenas da farinha 1 não atingiu o limite de 4,0 N/mm² previsto na norma EN 312-3 (1996).

Assim como ocorreu com os valores obtidos nos ensaios de resistência à compressão e à flexão, no ensaio da ligação interna, as chapas fabricadas com a farinha 1 obtiveram os piores resultados.

\section{Efeitos da relação madeira/cimento}

A tabela 8 apresenta os resultados para os diversos parâmetros, obtidos com o teor de $36 \%$ de farinha de madeira. O mesmo tratamento, feito para painéis com $25 \%$ de teor, foi adotado para painéis com $36 \%$ de teor de madeira. A granulometria adotada foi a da farinha 2, ou seja, intermediária, para permitir a comparação com outros ensaios.

Tabela 8. Valores médios das propriedades para painéis com $25 \%$ e $36 \%$ de farinha de madeira. Table 8. Results of the properties to panels with $25 \%$ and $36 \%$ of wood flours.

\begin{tabular}{lccccc}
\hline & \multicolumn{5}{c}{ Propriedades } \\
\hline & $\begin{array}{c}\text { Absorção 24h } \\
(\%)\end{array}$ & $\begin{array}{c}\text { Inchamento } \\
(\%)\end{array}$ & $\begin{array}{c}\text { Resistência à } \\
\text { compressão } \\
\text { (MPA) }\end{array}$ & $\begin{array}{c}\text { Resistência à flexão } \\
\text { estática } \\
\text { (MPA) }\end{array}$ & $\begin{array}{c}\text { Ligação interna } \\
\text { (MPA) }\end{array}$ \\
\hline Média teor 36 \% & $4,48 \mathrm{a}$ & $0,90 \mathrm{a}$ & $18,4 \mathrm{a}$ & $7,4 \mathrm{a}$ & $0,6 \mathrm{a}$ \\
CV $(\%)$ & 23,39 & 66,55 & 21,81 & 17,85 & 35,26 \\
Média teor 25\% & $4,99 \mathrm{a}$ & $0,90 \mathrm{a}$ & $16,7 \mathrm{a}$ & $5,4 \mathrm{a}$ & $0,7 \mathrm{a}$ \\
CV $(\%)$ & 19,10 & 15,36 & 17,66 & 14,62 & 32,81 \\
\hline
\end{tabular}

Letras diferentes denotam diferenças estatísticas ao nível de $5 \%$ de significância.

Analisando a tabela 8, observa-se que as propriedades de absorção e inchamento em espessura tiveram pequena variação, indicando que para essas propriedades a variação do teor de madeira não exerceu influência significativa.

Não houve diferença estatisticamente significativa para as propriedades de compressão paralela e flexão estática, o que pode ser explicado pelo elevado coeficiente de variação. $\mathrm{O}$ mesmo fato ocorre quando se analisam os valores para a ligação interna, ou seja, também não há diferença estatisticamente significativa entre os teores de $25 \%$ e $36 \%$ de madeira. Esse fato mostra que para esse intervalo do teor de fibras a matriz cimentícia continua sendo o fator preponderante. No entanto, os coeficientes de variação apresentados foram muito elevados, indicando que há outros fatores interferindo no ensaio.

Os valores obtidos para a resistência à compressão foram bastante elevados quando comparados aos trabalhos de Latorraca (2000) e de Grandi (1995). O primeiro encontrou valores médios entre 3,4 e 6,0 MPa, e o segundo achou valores de 3,0 a 9,0 MPa, ambos trabalhando com o teor de $36 \%$ de farinha de madeira. 
farinha:

Três aspectos devem ser considerados quando se comparam painéis com $25 \%$ e $36 \%$ de teor de

1. A utilização do teor de $25 \%$ de madeira em relação à massa de cimento gera painéis com elevada densidade, dificultando seu manuseio e conseqüentemente elevando o custo de sua utilização. $\mathrm{O}$ aumento do teor de madeira reduz a densidade do painel.

2. Não houve alteração significativa dos valores das propriedades analisadas quando se aumentou o teor de madeira para $36 \%$ em relação à massa de cimento, o que justifica a utilização da farinha de madeira com origem controlada para a fabricação de painéis.

3. Dentre os componentes do compósito, o cimento tem o maior custo e também gera uma elevada carga de poluição, o que pode justificar o aumento de teor de madeira na composição do painel.

\section{CONCLUSÕES}

Após a análise dos resultados, conclui-se que:

- Os resultados obtidos nos ensaios com os painéis mostraram que a variação da granulometria não teve nenhum efeito na absorção de água e no inchamento em espessura.

- Os valores obtidos para a tensão de ruptura tanto em compressão paralela quanto em flexão estática, nos ensaios dos painéis, para teores de $36 \%$ de madeira, foram elevados quando comparados a trabalhos de outros autores citados no texto.

- Os ensaios feitos com os painéis produzidos com a farinha 1 (mais fina) resultaram em menores valores tanto para a tensão de ruptura quanto para o módulo de elasticidade no ensaio à compressão paralela, comportamento semelhante ao observado nos ensaios em flexão estática.

- Os resultados dos ensaios em flexão dos painéis mostraram uma elevada correlação entre a resistência à flexão e a densidade.

- Nos ensaios de ligação interna, para o teor de $25 \%$ de farinha, verificaram-se os melhores resultados para a farinha 4 (mais grossa), mostrando assim a influência da distribuição granulométrica nessa propriedade.

- A variação do teor de madeira na produção de painéis de $25 \%$ para $36 \%$ não mostrou diferença estatisticamente significativa, no entanto, o coeficiente de variação foi elevado, justificando a utilização de farinha de madeira com granulometria controlada.

\section{REFERÊNCIAS}

ALBERTO, M. M.; MOUGEL, E.; ZOULALIAN, A. Compatibility if some tropical hardwoods species with Portland cement using isothermal calorimetry. Forest Products Journal, Madison, v. 50, n. 9, p. 83-88, 2000.

AMERICAN SOCIETY FOR TESTING AND MATERIALS. ASTM D 1037: standard methods of evaluating the properties of wood-based fiber and particle panel materials. [S.1.], 1982. (Annual Book of ASTM Standard).

ASSOCIAÇÃO BRASILEIRA DE NORMAS TÉCNICAS. NBR 7217: determinação da composição granulométrica dos agregados, modo de ensaio. Rio de Janeiro, 1982. 3 p.

BERALDO; A. L.; PIMENTEL, I.; LIMA, I. 1.; BARCHET, V. G. Efeito de tratamentos físico-químicos sobre a resistência à compressão de compósitos de madeira cimento. ENCONTRO BRASILEIRO EM MADEIRA E EM ESTRUTURAS DE MADEIRA, 6. 1998, Florianópolis. Anais do... Florianópolis: IBRAMEM, 1998. v. 4, p. 263-271.

COATES, G. R. Product application of wood-cement particleboards including applied finishes. INTERNATIONAL INORGANIC-BONDED WOOD AND FIBER COMPOSITE MATERIALS CONFERENCE, 4. 1994, Washington, DC. [Proceedings...]. Madison: Forest Products Society, 1994. v. 1, p. 189-192. 
EUROPEAN STANDARD. EN 1058: wood-based panels - determination characteristic values of mechanical properties and density. Brussels, 1995.

FAN, M.; DINWOODIE, J. M.; BONFIWLD, W. P.; BREESE, M. C. Dimensional instability of cement bonded particleboard behavior of cement paste and its contribution to the composite. Wood and Fiber Science, Madison, v. 3, n. 31, p. 306-315, 1999.

GRANDI, L. A. C. Placas pré-moldadas de argamassa de cimento e pó de serra. 128 f. Tese (Doutorado em Construções Rurais) - Faculdade de Engenharia Agrícola, Universidade Estadual de Campinas, Campinas, 1995.

IWAKIRI, S.; CUNHA, A. B.; ALBUQUERQUE, C. E. C.; GORNIAK, E.; MENDES, L. M. Resíduos de serraria na produção de painéis de madeira aglomerada de Eucalipto. Scientia Agrária, Curitiba, v. 1, n. $1-2$, p. $23-28,2000$.

LATORRACA, J. V. F. Eucalyptus spp. na produção de painéis de cimento madeira. 191 f. Tese (Doutorado em Engenharia Florestal) - Setor de Ciências Agrárias, Universidade Federal do Paraná, Curitiba, 2000.

MOSLEMI A. A.; GARCIA, J. F.; HOFSTRAND, A. D. Effect of various treatments and additives on wood-Portland cement water systems. Wood and Fiber science, Madison, v. 15, n. 2, p. 164-176, 1983.

VENTA, G. Gypsum fiberboard: a high performance specialty board INTERNATIONAL INORGANIC-BONDED WOOD AND FIBER COMPOSITE MATERIALS CONFERENCE, 4. 1994, Washington, DC. [Proceedings...]. Madison: Forest Products Society, 1994. v. 3, p. 66-77.

WEI, Y. M.; BUNICHIRO, T. Effects of five additive materials on mechanical and dimensional properties of wood cement-bonded boards. Tokyo: The Japan Wood Research Society, 2000. p. 437444.

WOLFE, R. W.; GNOLLI, A. Durability and strength of cement-bonded wood particle composites made from construction waste. Forest Product Journal, Madison, v. 2, n. 49, p. 24-31, 1999. 